X-ray data can as a rule be obtained from these materials, with consequent loss of information. The usefulness of the X-ray powder method is, moreover, further limited for clays because of the difficulty of preparing a truly randomly oriented powder specimen from aggregates of platy particles. It has long been appreciated, therefore, that the method of diffraction from a single erystal using a fine beam of electrons would be a useful one for the study of the structures of clay minerals, but this also is not without difficulties. The first is again the problem of preferred orientation, the platy clay particles tending to lie parallel to the supporting substrate, and therefore limiting the amount of diffraction data that can be recorded. The second difficulty is the interpretation of the observed electron diffraction intensities, because these are considerably affected by dynamical interaction between the diffracted and transmitted beams and by other factors which are not easily estimated quantitatively. It is interesting to compare the rather different ways in which these two obstacles have been regarded and dealt with in the Soviet Union (illustrated by Zvyagin's book) as compared with the approach by most other workers.

The Russian school, exemplified by Pinsker, Vainstein, Zvyagin and co-workers, have overcome specimen orientation difficulties by using specially designed electron diffraction cameras. These have allowed the tilting of the specimen stage to quite high angles, and have led to the use of the "oblique texture" method which gives a reasonable coverage of the diffraction data in reciprocal space. Most workers elsewhere have tended to make do with their electron microscopes for electron diffraction work, and the requirement of high resolution microscopy has (until very recently) militated against the provision of high-tilt specimen stage facilities. Of course, the electron diffraction camera user cannot see an image of the crystal which is giving the electron diffraction pattern, but in the study of particular specimens of clay minerals which are known to be homogeneous this is not a great disadvantage.

The difficulties concerning electron diffraction intensities have daunted many, but the Russian school has pressed on regardless. There is no doubt that, except in very favourable cireumstances, a highly accurate structure determination cannot be achieved using electron diffraction intensities, but erystallographers know well that even rough rolative intensities can yield a close approximation. to the correct atomic co-ordinates of a structure. It has thus been possible for Zvyagin and others to obtain useful structural information about clay minerals using electron diffraction which could not be determined in any other way.

The greater part of this book is concerned with the electron diffraction method and results, but a useful additional topic is dealt with in the first chapter, which describes the structures, polymorphs and polytypes of layered silicates. Here Zvyagin's systematic approach and specially devised notation are of great interest. The second chapter describes the electron diffraction apparatus, while the third and fourth chapters treat the theory of electron diffraction analysis in general, and in particular the "oblique texture" method applied to layered silicates. The fifth chapter gives examples of structure determinations of clay minerals which have been effected by the foregoing methods: these include kaolinite, coladonite, muscovite, phlogopite, nacrite, sepiolite and palygorskite.

For the reasons discussed here, relatively little mention is made of eombined electron microscopy and diffraction. With the recent development of high resolution electron microscopes with facilities for high angles of specimen tilt, the researcher can have the best of both worlds. Furthermore, dark-field imaging, using selected diffraction spectra, is proving important for the study of short range detail rather than the long range average structural features examined by X-ray diffraction. Thus the advantages of electron diffraction camera work are far fewer now than they were when this book was written in Russian in 1964. Others may now, using electron microscopes or cameras, take advantage of the methods and treatments set ont so clearly by Zvyagin.

The author has taken the opportunity, on the occasion of the book's translation from the Russian, to make some revisions, and to add new material concerning the serpentine minerals, halloysite, chlorites and disordered micas. The translation and technical reproduction of the book are both of a high standard, except in the case of the relatively few electron micrographs shown, which are less clear than the electron diffraction patterns.

This book can be read with profit by all those interested in the crystal structures of clay minerals or in the techniques of electron diffraction.

J. ZussmaN

\section{NON-FERROUS HEAVY METALS}

The Technology of Heavy Non-Ferrous Metals and Alloys

Copper, Nickel, Zinc, Tin, Lead. By J. H. Cairns and P. T. Gilbert. (Newnes International Monographs on Materials Science and Technology.) Pp. viii $+319+2$ plates. (London: George Newnes, Ltd., 1967.) 70s. net. THrs book sets out to emphasize practical applications rather than scientific aspects, and thereby defines its usefulness to metallurgists, engineers and designers. It achieves these objectives very well, particularly in the excellent summary of mechanical working processes and the five chapters on applications.

It is least successful when summarizing the physical and mechanical properties, although, in fairness, the flyleaf declares that this section is "not intended to be as detailed as the standard metallurgical textbooks". Typical of the surprising statements made here is that specific heat "increases slightly with rise of iemperature". followed by a general approximation of "5 per cent per $100^{\circ} \mathrm{C} "$, which is hardly slight. Nowhere is there any incorrect statement, but the appeal is more to the old fashioned concepts of many engineers and designers than to the new approach of the Council of Engineering Institutions.

No mention of powder metallurgy processes or products is made, except for sintered bronze bearings, and in the section on welding, the friction process does not appear. In assessing the appropriate properties for bearings, the importance of fatigue strength is omitted. Unusual entries in the index include "beer" and "whisky", for production of which considerable quantities of copper and nickel are employed. One excellent feature of the index is a separate list of those maddening specification numbers for metallic materials and components made from them. Few books in this field are produced outside the publications of the metal development associations, and so the authors are to be congratulated on this volume.

C. R. Totтu:

\section{NO VITALISM FOR CRICK}

\section{Of Molecules and Men}

By Francis Crick. Pp. xv +99 . (Seattle and London: University of Washington Press, 1966.) 30s. net.

For his John Danz Lectures, given at the University of Washington, Francis Criek took a title very appropriate for the field in which his work is so well known; but it was, perhaps, rather a quirk to choose to develop his theme in terms of an attack on vitalism. Is this not flogging a dead horso ? Crick is at pains to point out that the horse is still kicking, if faintly. "And so," he writes, "finally, we come to the question, 'Is vitalism dead?'. It 